\title{
MELARAS PIANO DENGAN SISTEM EQUAL-TEMPERED
}

\author{
Musmal \\ Dosen dan koordinator Bengkel Piano, Jurusan Musik, FSP ISI Yogyakarta.
}

HP: 08156854895

\begin{abstract}
This article theoretically discusses some basic techniques for tuning the piano through the equaltempered system. Based on long experience as a piano tuner, the author believe that this methodological steps of tuning technique can be mastered by anyone through intensive tuning excercises.
\end{abstract}

Keywords: Piano, equal tempered, tuning technique.

\begin{abstract}
Abstrak
Artikel ini secara teoretis membahas beberapa teknik dasar pelarasan piano dengan menggunakan sistem equal tempered. Berdasarkan pengalaman yang panjang sebagai seorang penala piano, penulis meyakini bahwa langkah-langkah metodologis teknik penalaan ini dapat dikuasai setiap orang melalui pelatihan-pelatihan menala secara intensif.
\end{abstract}

Kata kunci: Piano, equal tempered, teknik menala

\section{Pendahuluan}

Stem/Tuning atau melaras merupakan salah satu kebutuhan dasar bagi perawatan piano (maintenance). Keahlian dalam bidang ini sangat dibutuhkan, bukan hanya di negara-negara maju tapi juga di Indonesia maupun di negara-negara Asia Tenggara yang lainnya. Sementara banyak anggota masyarakat yang membutuhkan jasa dari keahlian ini, di Indonesia profesi sebagai pelaras piano (piano tuner/ piano stemer) termasuk pekerjaan yang jarang diminati. Dengan demikian tampaknya jumlah piano tuner di Indonesia masih belum seimbang dengan jumlah masyarakat yang memiliki piano yang umumnya dari golongan ekonomi menengah ke atas. Di samping pelanggan individual, jasa penalaan piano juga diperlukan oleh institusi pendidikan musik, baik formal maupun non formal. Untuk saat ini institusi pendidikan non musikpun tidak sedikit yang telah memiliki piano. Hotel-hotel berbintang dan tempat-tempat hiburan 
berkelas umumnya telah menjadikan kepemilikian piano sebagai salah satu standar pelayanan pelanggan. Dengan kata lain tidak perlu diragukan lagi bahwa profesi piano tuner memiliki prospek pekerjaan yang cukup menjanjikan.

Jarangnya orang yang tertarik pada profesi sebagai piano mungkin disebabkan karena hingga saat ini belum ada lembaga pendidikan yang membuka kursus ketrampilan di bidang ini. Sementara itu untuk menyelenggarakan kursus inipun dibutuhkan modal yang tidak sedikit karena harus menyediakan beberapa fasilitas yang tidak murah. Di samping memiliki beberapa piano untuk keperluan sampel pelarasan, juga perlu ruangan-ruangan untuk menampung piano-piano tersebut. Peralatan-peralatan khusus yang juga sangat jarang terdapat di toko-toko musik menjadi hambatan tersendiri. Jika kursus ini ada maka tentunya akan memakan biaya yang lebih mahal dari pada biaya kursus piano itu sendiri.

Melaras piano sebenarnya bukanlah hal yang rumit namun untuk melakukannya diperlukan kesabaran yang besar. Salah satu di antaranya proses pelarasan akan memakan waktu yang tidak sebentar. Untuk memiliki keahlian melaras piano seseorang tentunya perlu mengetahui teknik-teknik pelarasan yang mendasar. Dalam artikel ini diuraikan teori-teori dasar pelarasan piano dengan sistem equal-tempered.

\section{Pembahasan}

1. Sistem equal-tempered

Sistem melaras (stem) piano yang banyak digunakan saat ini di Eropa dan Amerika adalah melaras dengan system equal-tempered. Sistem tersebut secara teoritis adalah pembagian oktaf menjadi duabelas nada secara kromatis dibagi sama ukurannya. Secara matematis "ukuran" tempered kromatis yang sama, biasanya disebut sebagai 12 nada kromatis $\left(2^{1 / 12}\right)$. Ini adalah rasio frekuensi dari 2 frekuensi yang dipisahkan oleh tempered semitone yang sama.

Equal-tempered adalah sebuah temperamen musikal, atau sistem melaras (stem) menggunakan pasangan interval nada yang berdekatan yang disebut rasio frekuensi, biasanya dengan interval kuin (fifth), kuar (fourth) dan oktaf - dibagi dalam rangkaian langkah-langkah yang sama (rasio-rasio frekuensi yang sama) secara kromatis. Dalam musik diatonis, sistem yang lebih umum dapat juga disebut "twelve tone equal temperament". Sistem yang biasanya dilaras (stem) relatif dengan standar nada $440 \mathrm{~Hz}$, atau disebut diapason normal $\mathrm{A}=440$ di bawah $\mathrm{C}$ tengah.

Dalam praktek melaras, nada $A=440$, adalah sebagai patokan untuk melaras nada-nada berikutnya dalam rangkaian sistem equal-tempered. Dari nada A tersebut disamakan dengan oktaf atasnya secara unison (murni/ perfect). Selanjutnya dari nada $A=440$ 
dilaras dengan interval kuin di atasnya (nada $\mathrm{e}^{1}$ ), rasio dalam system equal-tempered, nada $\mathrm{a}=440 \mathrm{~Hz}$ ke kuin di atasnya (nada $e^{1}$ ) dilaras dengan mendeteksi hadirnya beat di antara kedua nada-nada tersebut. Biasanya kuin sempurna (perfect), nada $\mathrm{e}^{1}$ agak diturunkan sedikit hingga menghasilkan 1 atau 2 beat/ detik.

Dalam rangka menghasilkan akurasi yang absolut dalam merangkai sistem stem equal-tempered, penyetem piano dituntun dengan beat, gelombang atau pulsasi yang terbentuk dari sebuah interval bila dibunyikan secara bersamaan. Kata ini mengacu pada tiga kata yang bermakna sama, sebuah fenomena yang terjadi dalam interval tertentu ketika dua nada terdengar bersamasama di-stem tidak tepat. Istilah-istilah ini tidak harus bingung dengan "gelombang suara" istilah atau "getaran" begitu sering digunakan dalam diskusi-diskusi teori suara.

Membuat temperament sebuah interval dan menimbulkan beat, ini diakibatkan oleh fluktuasi intensitas di antara nada interval kuin. Kecepatan beat/ detik dapat dihasilkan dengan menaikkan/ menurunkan tensi dawai dari sebuah interval kuin dengan alat khusus yang disebut tuning tool atau tuning hammer (Fischer, 2006: 111). Melaras piano dengan menahan durasi nada lebih panjang, beat dapat dengan mudah dideteksi. Interval unison dapat menimbulkan efek khas: bila dua nada sesuai pitch-nya, namun belum identik. Tetapi bila dua nada semakin mendekati unison, kecepatan beat semakin melambat dan akhirnya menghilang, membentuk resonansi unison sempurna (Perfect).

Langkah-langkah yang digunakan dalam praktek melaras piano umumnya adalah:

a. Melaras tiga dawai dalam sebuah pitch yang sama disebut chord. Bagi pemula tahap dasar ini sangat penting untuk melaras ketiga dawai menjadi satu pitch yang sama.

b. Mengindentifikasi beat (denyut) di antara interval kuin dan kuar.

c. Merangkai (setting) tempered dari nada e hingga nada bes ${ }^{1}$ (Lihat figur keyboard).

d. Timing atau waktu dan ketepatan pitch sebagai pedoman dalam melaras/ tuning sebuah piano.

Piano memiliki lebih dari dua ratus dawai (dawai) yang direntang melintang pada kerangka besi (plate) dengan tingkat ketegangan relatif tinggi (kira-kira 16-20 ton). Masingmasing ujung dawai ada yang dikaitkan pada paku pengait yang disebut hitch pin, dan ujung yang lain dilingkarkan dan digulung pada penggulung yang disebut tuning pin yang tertanam pada bilah kayu yang disebut pin block. Rentangan dawai piano umumnya terdiri atas tiga dawai untuk masing-masing tingkat ketinggian (pitch), dan untuk nada bas terdiri dari dua dawai dan satu dawai.

Pitch masing-masing nada dawai tergantung pada ketegangannya. Ketegangan masing-masing dawai dapat diatur dengan tuning hammer 
atau tuning tool. Dengan memutar tuning pin, maka ketegangan dawai dapat dinaikan dan diturunkan sesuai dengan pitch yang diinginkan. Dari uraian tersebut dapat diambil suatu pengertian bahwa tuning atau stem adalah mengatur atau menyetel ketegangan masing-masing dawai piano sehingga pitch selaras dengan ketentuan-ketentuan akustik atau sistem tuning piano yang digunakan.

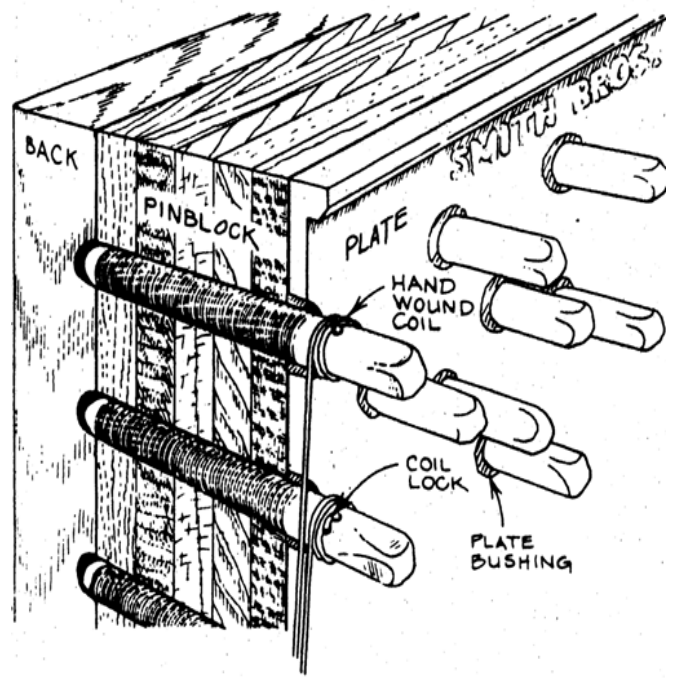

Gambar 1: Susunan plate dan tuning pin yang tertanam pada pinblock.

\section{Mengapa Piano harus di-stem/ dilaras}

Sebagian faktor penting penyebab tuning piano selalu berubah adalah perubahan kelembaban udara dari musim ke musim, seperti di Indonesia misalnya terjadi perubahan tingkat kelembaban udara dari musim hujan ke musim kemarau atau sebaliknya. Perubahan pada kelembaban udara tersebut mempengaruhi semua merk piano, baik itu piano bagus atau piano jelek, piano baru atau piano lama, yang selalu dimain- kan atau tidak pernah dimainkan. Dari beberapa penelitian para ahli diketahui bahwa, perubahan ekstrim pada kelembaban udara sangat mempengaruhi soundboard yang terdapat di antara back dan kerangka besi piano (plate).

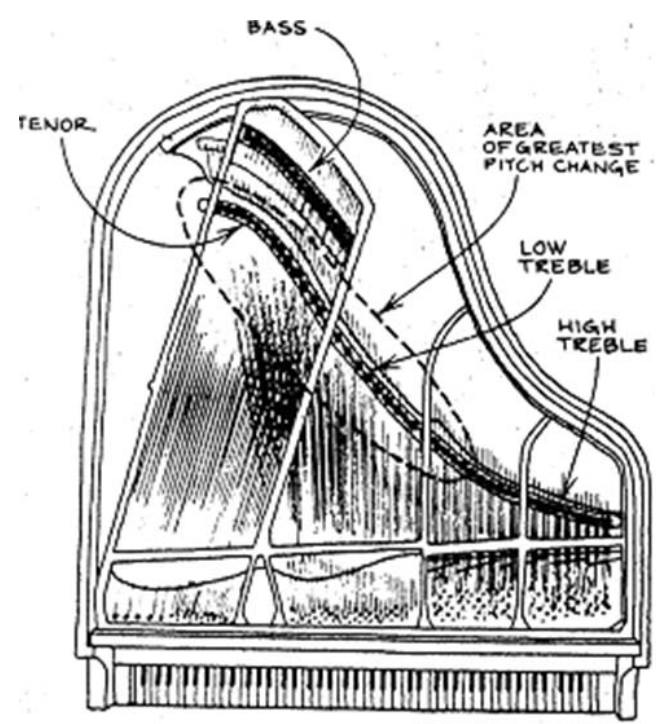

Gambar 2: Wilayah (range) suara piano.

Permukaan soundboard dapat bergelombang (tidak rata) oleh pengaruh embun dari kelembaban udara, dan mendorong dawai pada bridge yang terletak disepanjang soundboard. Dengan demikian ketegangan dawai akan cenderung meningkat, dan menyebabkan pitch berubah. Sebaliknya dalam cuaca kering atau panas komponen-komponen piano kemudian akan memuai, ketegangan dawai piano akan cenderung menurun dan membuat pitch piano juga akan berubah (Fine, 1987: 168). Dalam beberapa penelitian di Amerika, rangkaian pitch yang cenderung berubah adalah pada area 
treble bawah dan bas (Perhatikan pada gambar di bawah). Oleh karena itu area pitch treble bawah dan bas paling sensitive terhadap perubahan cuaca (Fine, 1987: 169).

Perubahan pitch pada piano banyak dipengaruhi oleh iklim lokal serta bagaimana respon piano terhadap perubahan kelembaban udara. Di Indonesia pada umumnya terdapat dua musim, yaitu musim penghujan dan musim panas atau kemarau. Perubahan kelembaban udara terjadi dari musim kemarau ke musim hujan, dan sebaliknya dari musim hujan ke musim kemarau (masa pancaroba). Musim hujan terjadi pada bulan September hingga bulan Pebruari. Sedangkan musim panas atau kemarau terjadi pada bulan Maret hingga bulan Agustus. Enam bulan selama musim hujan merupakan waktu yang panjang, meskipun kelembaban udara demikian tinggi, dalam kondisi demikian papan soundboard akan dapat lebih stabil dengan memasang pemanas (heater), demikian juga sebaliknya selama musim panas (kemarau) meskipun kelembaban udara demikian rendah, papan soundboard dapat bertahan setabil.

Dari uraian tersebut di atas disarankan menyetem piano dua kali setahun, pertama pada awal musim hujan kira-kira bulan September, dan pada awal musim panas atau kemarau kira-kira pada bulan Maret.Walaupun demikian, seberapa sering dilakukan stem piano tidak hanya tergantung pada kualitas piano atau perubahan kelembaban udara di dalam suatu ruangan sebuah piano ditempatkan, tetapi juga tergantung dari kemampuan pendengaran pemilik atau pemain piano mendeteksi bahwa piano tidak stem (in tune) dan juga budget keuangan. Walaupun dua kali setahun menyetem piano merupakan keputusan yang ideal, namun bila piano jarang dimainkan, satu kali setahun sudah cukup, walau itu tidak disarankan.

Kadang-kadang pemilik piano mempertimbangkan, seberapa pentingkah harus menyetem piano?, Apakah piano akan rusak bila tidak di-tuning? Inilah masalah utama yang sering terjadi di masyarakat, namun hampir tidak pernah didiskusikan. Sebaliknya sebagian teknisi (tukang stem), agar piano di-tuning, mereka berusaha menawarkan alasan-alasan yang tidak logis, missalnya, piano harus dipasang pemanas (heater), bila tidak piano akan rusak.

Dalam beberapa kasus selama 15 tahun penulis menyetem di berbagai tempat di Jawa Tengah dan Jakarta, banyak masyarakat pemilik piano bahkan pemain piano profesionalpun belum memahami masalahmasalah seperti tersebut di atas. Bila penulis berpendapat bahwa bila piano tidak dituning bertahun-tahunpun, piano tidak akan rusak. Hanya saja konsekuensi logis dari kondisi piano demikian adalah pembentukan estetika suara bagi pendengaran pemain dan audiens akan sangat berpengaruh bila talaan piano tidak stem. 


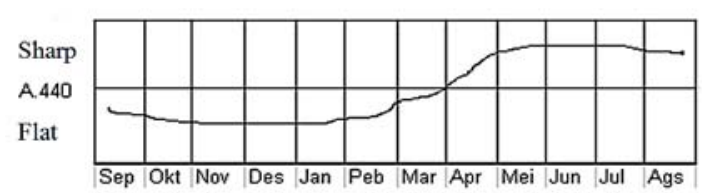

Gambar 3: Grafik kecenderungan pitch piano naik dan turun dari musim ke musim

\section{Metode Membentuk Rangkaian Equal-Tempered}

Tahap dasar oleh pemula dalam menyetem piano adalah melaras tiga dawai menjadi satu pitch tertentu. Misalnya, meredam (mute) dua dawai nada a dengan alat (damper) dapat disesuaikan dengan garpu tala diapason normal 440. Selanjutnya damper pindahkan ke sisi pinggir tiga dawai, sesuaikan senar berikut dengan dawai yang telah di stem, demikian seterusnya hingga ketiga dawai menjadi identik dalam satu pitch. Praktek menyetem tahap dasar ini sangat penting bagi pemula untuk melatih mengidentifikasi pitch ketiga dawai. Untuk membiasakan pendengaran biasanya praktek tersebut dilakukan dengan berulangulang sehingga menghasilkan pitch yang identik dan waktu (timing) sesingkat mungkin; waktu (timing) yang ideal paling lambat satu menit untuk setiap senar.

Langkah kedua, menyetem pitch dengan waktu yang ideal tercapai, dilanjutkan merangkai (setting) equal-tempered sebagai pedo- man dalam melaras nada-nada atas (diskan) dan nada-nada bawah (baskan). Rangkaian equal-tempered (setting) merupakan acuan untuk melaras seluruh dawai piano yang dibentuk dengan menggunakan metoda beating di antara interval kuin dan kuar. Wilayah rangkaian (setting) equal-tempered adalah dari nada e hingga bes ${ }^{1}$ seperti figur berikut:

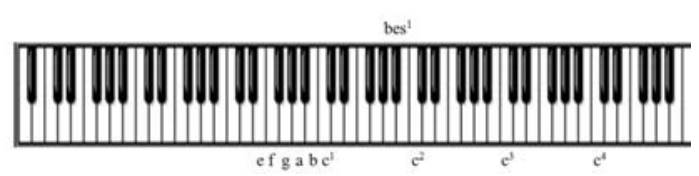

Gambar 4: Rangkaian bilah keyboard piano.

Setelah melaras nada a dengan garpu tala atau alat tuning elektrik dengan diapason normal nada $\mathrm{a}=440$ Hz. Kemudian tuning oktaf atas $a^{1}$ dibandingkan dengan nada a bawah menjadi datar tanpa gelombang (flatter) atau murni (perfect). Selanjutnya tuning dengan rangkaian sebagai berikut:

Tabel 1: Prosedur Penalaan Piano

\begin{tabular}{|c|c|c|c|c|c|c|}
\hline No. & Nada & Tune & Nada & Posisi & Beating & $\begin{array}{l}\text { Kontrol } \\
\text { dengan }\end{array}$ \\
\hline 1. & $a$ & $\mathrm{Ke}$ & $\mathrm{e}^{1}$ & $\begin{array}{l}\text { Kuin } \\
\text { atas }\end{array}$ & $\begin{array}{l}1 \text { atau } \\
\text { 2/detik }\end{array}$ & $\begin{array}{c}\text { Nada } \mathrm{a}^{1} \\
\text { beat sama }\end{array}$ \\
\hline 2. & $\mathrm{e}^{1}$ & $\mathrm{Ke}$ & $\mathrm{e}$ & $\begin{array}{r}\text { Oktaf } \\
\text { bawah }\end{array}$ & Datar/flat & \\
\hline 3. & e & ke & $b$ & $\begin{array}{l}\text { Kuin } \\
\text { atas }\end{array}$ & $\begin{array}{l}1 \text { atau } \\
\text { 2/detik }\end{array}$ & $\begin{array}{c}\text { Nada }^{1} \\
\text { beat sama }\end{array}$ \\
\hline 4. & $\mathrm{~b}$ & ke & fis $^{1}$ & $\begin{array}{l}\text { Kuin } \\
\text { atas }\end{array}$ & $\begin{array}{l}1 \text { atau } \\
\text { 2/detik }\end{array}$ & \\
\hline 5. & fis $^{1}$ & ke & fis & $\begin{array}{l}\text { Oktaf } \\
\text { bawah }\end{array}$ & Datar/flat & \\
\hline 6. & fis & ke & cis $^{1}$ & $\begin{array}{l}\text { Kuin } \\
\text { atas }\end{array}$ & $\begin{array}{l}1 \text { atau } \\
\text { 2/detik }\end{array}$ & $\begin{array}{c}\text { Nada fis }{ }^{1} \\
\text { beat sama }\end{array}$ \\
\hline 7. & cis $^{1}$ & ke & gis 1 & $\begin{array}{l}\text { Kuin } \\
\text { atas }\end{array}$ & $\begin{array}{l}1 \text { atau } \\
\text { 2/detik }\end{array}$ & \\
\hline
\end{tabular}





\begin{tabular}{|c|c|c|c|c|c|c|}
\hline 8. & $\begin{array}{l}\text { gis }{ }^{1 /} \\
\mathrm{as}^{1}\end{array}$ & ke & $\begin{array}{l}\text { gis/ } \\
\text { as }\end{array}$ & $\begin{array}{c}\text { Oktaf } \\
\text { bawah }\end{array}$ & $\begin{array}{c}\text { Datar/fl } \\
\text { at }\end{array}$ & \\
\hline 9. & as & ke & $\mathrm{es}^{1}$ & Kuin atas & $\begin{array}{l}1 \text { atau } \\
\text { 2/detik }\end{array}$ & $\begin{array}{c}\text { Nada as }^{1} \\
\text { beat } \\
\text { sama }\end{array}$ \\
\hline 10. & $\mathrm{es}^{1}$ & ke & bes $^{1}$ & Kuin atas & $\begin{array}{l}1 \text { atau } \\
\text { 2/detik }\end{array}$ & \\
\hline 11. & bes $^{1}$ & ke & bes & $\begin{array}{l}\text { Oktaf } \\
\text { bawah }\end{array}$ & $\begin{array}{c}\text { Datar/fl } \\
\text { at }\end{array}$ & \\
\hline 12. & bes & ke & $f^{1}$ & Kuin atas & $\begin{array}{l}\text { 1 atau } \\
\text { 2/detik }\end{array}$ & $\begin{array}{l}\text { Nada bes } 1 \\
\text { beat sama }\end{array}$ \\
\hline 13. & $f^{1}$ & ke & $f$ & $\begin{array}{c}\text { Oktaf } \\
\text { bawah }\end{array}$ & $\begin{array}{c}\text { Datar/fl } \\
\text { at }\end{array}$ & \\
\hline 14. & $f$ & ke & $\frac{c^{1}}{1}$ & Kuin atas & $\begin{array}{l}1 \text { atau } \\
2 / \text { detik }\end{array}$ & $\begin{array}{c}\text { nada }^{1} \\
\text { beat } \\
\text { sama }\end{array}$ \\
\hline 15. & $\frac{\mathrm{c}^{1}}{1}$ & ke & $g^{1}$ & Kuin atas & $\begin{array}{l}\text { 1 atau } \\
\text { 2/detik }\end{array}$ & \\
\hline 16. & $g^{1}$ & ke & g & $\begin{array}{l}\text { Oktaf } \\
\text { bawah }\end{array}$ & $\begin{array}{c}\text { Datar/fl } \\
\text { at }\end{array}$ & \\
\hline 17. & $g$ & ke & $\mathrm{d}^{1}$ & Kuin atas & $\begin{array}{l}\text { 1 atau } \\
\text { 2/detik }\end{array}$ & $\begin{array}{c}\text { nada g}^{1} \\
\text { beat } \\
\text { sama }\end{array}$ \\
\hline 18. & $\mathrm{~d}^{1}$ & ke & $a^{1}$ & Kuin atas & $\begin{array}{l}1 \text { atau } \\
\text { 2/detik }\end{array}$ & $\begin{array}{c}\text { nada a } \\
\text { beat } \\
\text { sama }\end{array}$ \\
\hline
\end{tabular}

Rangkaian (setting) equaltempered yang telah selesai seperti langkah-langkah tersebut di atas, dapat dikontrol dengan cara mendengarkan fibrasi interval ters/ sixth, dari nada a ke cis1, atau e ke cis1, dimainkan secara kromatis dan dengarkan fibrasinya, makin ke atas makin cepat fibrasinya. Sebagai catatan, untuk menentukan jumlah beat/detik, dalam prakteknya, tuning kuin secara sempurna (perfec), kemudian turunkan nada atasnya sehingga menemukan 1 atau 2 beat/detik. Dan waktu (timing) yang ideal praktek merangkai equaltempered kurang lebih dalam satu jam.

Selanjutnya berpedoman dengan rangkaian equal-tempered yang telah selesai dirangkai, tuning atau stem piano dapat dilanjutkan dengan menyesuaikan rangkaian oktaf ke atas dimulai dari nada: b1 ke b2; c2 ke c3; cis2 ke cis3, dan seterusnya, semuanya merupakan oktaf sempurna (Perfect) hingga nada-nada tinggi terakhir, dengan target waktu kurang lebih satu jam. Kemudian dilanjutkan pada nada-nada oktaf bawah dari nada es1 ke es; d1 ke d; cis1 ke cis; c1 ke c; dan seterusnya hingga nada-nada $\mathrm{A}$ bas terakhir sub-kontra, juga dengan target watu kurang lebih satu jam.

Langkah-langkah tersebut di atas sebaiknya dilakukan berkali-kali dengan membiasakan pendengaran saat mengidentifikasi pitch setiap nada dan target waktu maksimal 3 jam untuk sebuah piano yang dilaras.

\section{Penutup}

Makalah ini merupakan informasi teoritis dan pengalaman penulis sebagai pelaras piano yang dilakukan sejak tahun 1995 hingga saat ini. Melaras (tuning) piano merupakan keterampilan yang dapat dikuasai dan dipelajari, tentu saja dengan ketekunan dan kesabaran serta ketelitian mengidentifikasi pitch dan beat. Melaras piano dengan sistem equal-tempered merupakan keterampilan yang dapat dibentuk dengan latihan-latihan seperti tersebut yang telah dijelaskan di atas hingga mencapai target waktu yang ideal untuk penalaan sebuah piano, yaitu tiga jam.

\section{Referensi}

Culver, Charles A. 1956. Musical Acoustic, $4^{\text {Th }}$ Edition. New 
14 | Musmal, Melaras Piano dengan Sistem Equal-Tempered

York: McGraw-Hill Book Company.

Fine, Larry. 1987. The Piano Book, A Guide To Buying A New or Used Piano, Boston, Massachusetts: Brook-side Press,

Fischer, J. Cree. 2006. Piano Tuning: A Simple and Accurate Method for Amateurs, New York: Dover Publications, Inc., n.d.

Jones, George Thaddeus. 1974.Music Theory, New York: Barnes \& Noble Books.

Linley, Mark. 1984. Equal Tempered, Stanley Sadie (Ed.), The New Grove Dictionary of Music and Musicians. London: Mac Millan Press Ltd.

Summer, William Leslie. 1966. The Pianoforte, London: Macdonald and Co, Ltd. 